\title{
Position Sensorless Control of PMSM Based on a Sliding Mode Observer
}

\author{
Zhang zheng ${ }^{\text {a, }}$, Narisha ${ }^{\mathrm{a},{ }^{*}, \text { Wang xudong }}{ }^{\mathrm{a}}$ \\ ${ }^{\mathrm{a}}$ Harbin University of Science and Technology, No.52 Xufu Road, Harbin 150080, China \\ *Corresponding Author: narisha.ao@hrbust.edu.cn
}

\begin{abstract}
Sliding mode observer (SMO) for permanent magnet synchronous motor (PMSM) speed and rotor position is used in this paper to realize sensorless control. According to the PMSM mathematical model and the sliding mode control theory, the SMO model was given. The stability condition of SMO is studied to make sure that the observer is stable in converging to the sliding mode plane. This paper analyzes the structure and performance of the proposed SMO strategy with SIMULINK based simulation. Simulation results are presented to verify the proposed sensorless control algorithm.
\end{abstract}

Keywords: permanent magnet synchronous motor, position sensorless, sliding mode observer.

\section{Introduction}

Permanent magnet synchronous machines (PMSM) have been increasingly applied for drive applications due to their simple structure, high power density, high torque to inertia ratio and high efficiency. To achieve the efficient vector control of a PMSM, knowledge of rotor position is necessary. Usually the rotor position angle is measured by a Resolver, or other absolute encoder. However, the presence of such sensors increases the cost and encumbrance of the overall system as well as reduces its robustness and reliability. Furthermore the sensors are expensive and very sensitive to the environmental constraints such as vibration and temperature. To overcome these problems, instead of using the position sensors, the sensorless control method has been developed to control the motor using the estimated values of the position and velocity of the rotor ${ }^{(1-3)}$.

Such as high-frequency injection method, extended Kalman filter, observer estimation method, flux estimation, artificial intelligence estimation method, adaptive reference control method has been extensively studied. High-frequency injection method at high speed, the back-electromotive force is too large, furthermore the speed and position detection accuracy of the rotor is deteriorated, system stability is poor; Extended Kalman filter method has a large calculate volume, the algorithm requires high carries for the chip, the stator voltage is very small Near zero speed, estimation error of the status will be affected by increases of measurement error and uncertainty of motor model; Artificial intelligence estimation method and technology issues is not mature yet, it need specialized hardware support and more difficult, therefore, it is difficult for the practical application; adaptive reference control method exist a problem how to choose the model reference adaptive rational adaptive law, to ensure system stability and robustness of the parameters at the same time improving the convergence rate of this method ${ }^{(4-6)}$. Compared with other methods, sliding mode variable structure can response fast, have good robustness and ensure that the system is asymptotically stable, at the same time its algorithm is simple and easy to achieve on project ${ }^{(7-8)}$.

To cope with the foregoing problems, this paper presents a sensorless vector control algorithm for PMSM. The rotor position angle is estimated by a sliding mode observer. Simulation results are used to verify its validity.

\section{Mathematical Model Of PMSM}

In order to create a mathematical model of PMSM sine wave, make the following assumptions: the effect of magnetic saturation of the rotor core and stator are ignored, the hysteresis loss and eddy current of motor are ignored; Armature reaction magnetic field generated by the permanent magnet excitation field and three-phase windings in the air gap are sinusoidal distribution; Steady-state operation, the phase windings induced electromotive force waveform is a sine wave. 
The current state equation of surface mounted PMSM in the synchronous rotating coordinate (d-q coordinates) of:

$$
\left[\begin{array}{c}
\dot{i}_{\mathrm{d}} \\
\dot{\mathrm{q}}_{\mathrm{q}}
\end{array}\right]=\left[\begin{array}{ccc}
-\frac{R}{L} & p_{\mathrm{n}} \omega_{\mathrm{r}} & 0 \\
-p_{\mathrm{n}} \omega_{\mathrm{r}} & -\frac{R}{L} & -\frac{p_{\mathrm{n}} \Psi_{\mathrm{f}}}{L}
\end{array}\right]\left[\begin{array}{c}
i_{\mathrm{d}} \\
i_{\mathrm{q}} \\
\omega_{\mathrm{r}}
\end{array}\right]+\left[\begin{array}{cc}
\frac{1}{L} & 0 \\
0 & \frac{1}{L}
\end{array}\right]\left[\begin{array}{l}
u_{\mathrm{d}} \\
u_{\mathrm{q}}
\end{array}\right]
$$

In the equation: $i_{d}, i_{q}, u_{d}, u_{q}$ are currents and voltages of synchronous rotating coordinate system; $R, L$ are the stator resistance and inductance of motor; $P_{n}, \psi_{f}$ are pole pairs number of motor and the rotor flux, $\omega_{r}$ are mechanical angular velocity of the motor.

In the stationary-phase permanent magnet synchronous motor coordinates, coordinates and static two-phase model of the two-phase synchronous rotating coordinate system is shown in Figure 1.

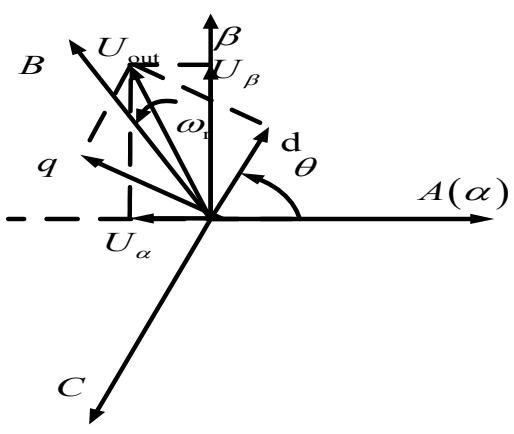

Fig. 1. Diagram coordinates model of PMSM.

The equation (1) is converted to the current state of the equation of stationary coordinate ( $\alpha-\beta$ coordinates):

$$
\left[\begin{array}{l}
\dot{i}_{\alpha} \\
\dot{i}_{\beta}
\end{array}\right]=\left[\begin{array}{cc}
-\frac{R}{L} & 0 \\
0 & -\frac{R}{L}
\end{array}\right]\left[\begin{array}{l}
i_{\alpha} \\
i_{\beta}
\end{array}\right]+\left[\begin{array}{cc}
\frac{1}{L} & 0 \\
0 & \frac{1}{L}
\end{array}\right]\left[\begin{array}{ll}
u_{\alpha} & -e_{\alpha} \\
u_{\beta} & -e_{\beta}
\end{array}\right]
$$

Where:

$$
\left\{\begin{array}{l}
e_{\alpha}=-\Psi_{\mathrm{f}} \omega_{\mathrm{e}} \sin \theta \\
e_{\beta}=\Psi_{\mathrm{f}} \omega_{\mathrm{e}} \cos \theta
\end{array}\right.
$$

In the equation: $i_{\alpha}, i_{\beta}, u_{\alpha}, u_{\beta}$ are currents and voltages of the stationary coordinate system; $e_{\alpha}, e_{\beta}$ are electromotive force of the stationary coordinate system; $\omega_{e}, \theta$ are rotor electrical angular velocity and electrical angle of the motor.

\section{Design of Control System Based On Sliding Mode Observer}

By equation (3) shows the back EMF contains a rotor position signal, the observer can be extracted. The sliding mode observer which is designed in this article puts the stator current under static coordinates system as input of observer, through the observation of the motor back EMF, to extract rotor speed and position information of the measurements.
According to equation(2) given a current state equation of permanent magnet synchronous motor under stationary coordinate system, based on the theory of sliding mode variable structure control, we can construct the current sliding mode observer equation:

$$
\begin{aligned}
& \frac{d \hat{i}_{\alpha}}{d t}=-\frac{R}{L} \hat{i}_{\alpha}+\frac{U_{\alpha}}{L}-\frac{l_{1}}{L} \operatorname{sign}\left(\hat{i}_{\alpha}-i_{\alpha}\right) \\
& \frac{d \hat{i}_{\beta}}{d t}=-\frac{R}{L} \hat{i}_{\beta}+\frac{U_{\beta}}{L}-\frac{l_{1}}{L} \operatorname{sign}\left(\hat{i}_{\beta}-i_{\beta}\right)
\end{aligned}
$$

Then, we can get current error equations as follows:

$$
\begin{aligned}
& \frac{d \bar{i}_{\alpha}}{d t}=-\frac{R}{L} \overline{i_{\alpha}}+\frac{e_{\alpha}}{L}-\frac{l_{1}}{L} \operatorname{sign} \overline{i_{\alpha}} \\
& \frac{d \overline{i_{\beta}}}{d t}=-\frac{R}{L} \overline{i_{\beta}}+\frac{e_{\beta}}{L}-\frac{l_{1}}{L} \operatorname{sign} \overline{i_{\beta}}
\end{aligned}
$$

The key of sliding mode variable structure control design is to control the function $u(x)$ and design of switching surface $s(x)$, here we choose constant switch control function $u=u_{o} \operatorname{sgn}(s(x))$ as control function, $u_{o}$ is taken as $-l_{l}$, to ensure that the condition $S S=0$ of sliding mode reaching is established, the value of $l_{l}$ is related to the stability of the system, here's an analysis of the range of the $l_{l}$.

By the previous conclusions, we have:

$$
\overline{i_{\alpha}} \dot{i_{\alpha}}==\left\{\begin{array}{l}
\frac{1}{L} \overline{i_{\alpha}}\left(e_{\alpha}-l_{1}\right)-\frac{R}{L} \bar{i}_{\alpha}^{2}, \overline{i_{\alpha}}>0 \\
\frac{1}{L} \overline{i_{\alpha}}\left(e_{\alpha}+l_{1}\right)-\frac{R}{L} \bar{i}_{\alpha}^{2}, \overline{i_{\alpha}}<0
\end{array}\right.
$$

Similarly, we have:

$$
\bar{i}_{\beta} \dot{\dot{i}_{\beta}}==\left\{\begin{array}{l}
\frac{1}{L} \bar{i}_{\beta}\left(e_{\beta}-l_{1}\right)-\frac{R}{L} \bar{i}_{\beta}^{2}, \bar{i}_{\beta}>0 \\
\frac{1}{L} \bar{i}_{\beta}\left(e_{\beta}+l_{1}\right)-\frac{R}{L} \bar{i}_{\beta}^{2}, \bar{i}_{\beta}<0
\end{array}\right.
$$

Arrival condition is:

$$
s \dot{s}<\left[\begin{array}{ll}
\overline{i_{\alpha}} & \bar{i}_{\beta}
\end{array}\right]\left[\begin{array}{l}
\frac{d \overline{i_{\alpha}}}{d t} \\
\frac{d \overline{i_{\beta}}}{d t}
\end{array}\right]=\left[\begin{array}{ll}
\overline{i_{\alpha}} \frac{d \overline{i_{\alpha}}}{d t} & \overline{i_{\beta}} \frac{d \overline{i_{\beta}}}{d t}
\end{array}\right]<0
$$

That is to satisfy the $\overline{i_{\alpha}} \frac{d \overline{i_{\alpha}}}{d t}<0$ and $\overline{i_{\beta}} \frac{d \overline{i_{\beta}}}{d t}<0$

Visible only when $l_{1}>\max \left(\left|e_{\alpha}\right|,\left|e_{\beta}\right|\right)$, the above conditions are met, so that we can guarantee the stability of the error equation. In practice, $l_{l}$ can't take too much, otherwise it will increase the chattering noise, causing unnecessary estimation error.

Switching surface $s(x)$ only to select current error value, namely $S(x)=\left[\bar{i}_{\alpha}, \bar{i}_{\beta}\right]$, visible when the sliding mode motion occurs, as $S(x)=0$ and $\dot{S}(x)=0$, the equivalent 
control began to work, $u_{\text {efa } a}=\left[-l_{1} \operatorname{sighi\overline {a}_{\alpha \sigma }}\right]_{\text {eq }}=e_{\alpha}$ 、 $u_{e q \beta}=\left[-l_{1} \operatorname{signi} \bar{\beta}_{\beta s}\right]_{Q q}=e_{\beta}$, it is under the action of that, the stator current estimates track the actual value, so that the equivalent control component and the back EMF is consistent, to observe the effect of anti electromotive force.

$u_{\text {ega }} 、 u_{\text {og } \beta}$ is a switch signal of current error, not only contains the information of back EMF, but also the high frequency signal of control, making switch control measure through a low-pass filter to get the equivalent control, namely the estimated back EMF $\hat{e}_{\alpha} 、 \hat{e}_{\beta}$.

$$
\left\{\begin{array}{l}
\hat{e}_{\alpha}=\frac{\omega_{0}}{\omega_{0}+s} u_{\text {eq } \alpha} \\
\hat{e}_{\beta}=\frac{\omega_{0}}{\omega_{0}+s} u_{\text {eq } \beta}
\end{array}\right.
$$

$\omega_{0}$ is the cut-off frequency, the cut off frequency of low pass filter with different rotor speed is not the same, the cut-off frequency and speed have the following relations $\omega_{0}=\omega_{\mathrm{e}} / K$, under the condition of changes in speed, cut-off frequency, low pass filter transfer function is:

$$
G(j \omega)=\frac{\omega_{0}}{\omega_{0}+j \omega}=\frac{1}{1+j K}
$$

The rotor position signal can be extracted from the estimated back EMF

$$
\hat{\theta}=-\arctan \left(\hat{e}_{\alpha} / \hat{e}_{\beta}\right)
$$

Due to the low-pass filtering property will bring some phase lag, so it is necessary for phase lag compensation in practical application

$$
\begin{gathered}
\hat{\theta}=\hat{\theta}+\Delta \theta \\
\Delta \theta=\arctan \frac{\omega^{\prime}}{\omega_{0}}
\end{gathered}
$$

Where is the amount of compensation, is equal to the given speed in the steady state, when the transient is equal to the estimated speed. The rotor speed is also obtained by the estimation of back EMF

$$
\hat{\omega}_{\mathrm{e}}=\frac{\sqrt{\hat{e}_{\alpha}{ }^{2}+\hat{e}_{\beta}{ }^{2}}}{\psi_{\mathrm{f}}}
$$

The sliding mode observer for permanent magnet synchronous motor without position sensor control system block diagram is shown in figure 2 .

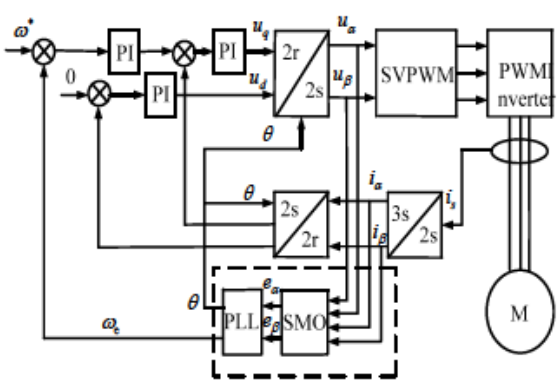

Fig.2. Block diagram of control system based on sliding mode observer

By analyzing the working principle of the sliding mode observer, we can know the sliding mode observer is used to observe the back EMF ,due to the presence of high frequency chattering in sliding mode, , the back EMF also has the high frequency chattering, and the rotor position and speed signal is extracted from the back EMF, if directly through the operation of formula to extract the signal, it will directly bring the buffeting of back EMF into formulas, The estimated rotor speed and position also exist buffeting, causing the estimated rotor speed and position also exist buffeting. Therefore, starting from the angle of eliminating the influence in back EMF of high-frequency components on rotor speed and position signal, design the rational rotor speed and position information extraction unit, in order to avoid the influence of back EMF buffeting on the estimation of rotor speed and position, this article introduces the phase-locked loop position detection system.

The sliding mode observer and phase-locked loop position detection system combine together, first through the sliding mode observer to estimate the motor back EMF, and then construct rotor position detection unit based on phase-locked loop structure, extracting motor rotor position and speed signals from the estimated back EMF. Here take the motor back EMF estimation as PLL input signal, according to the relation between the the back EMF and the rotor position, build a rotor position detection system of a phase locked loop, to extract the position signal contained in back EMF, as shown in figure 3. 


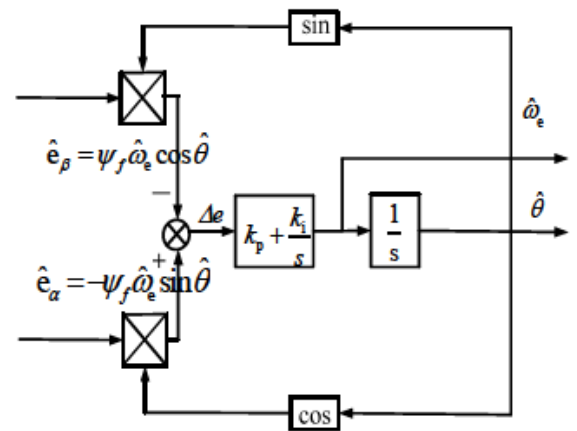

Fig.3. Phase-locked loop position detection system

\section{Simulation and Result Analysis of the Control System}

This paper puts forward a sensorless control algorithm based on the sliding mode observer (SMO). In order to validate the control effect of the control algorithm on the PMSM without position sensor, the simulation study is carried out by means of Matlab/Simulink.with the vector control method, and PMSM's stator is using star connection method. Motor parameters are as follows, $R=2.875 \Omega, \quad L_{d}=0.0085 \mathrm{H}, \quad L_{q}=0.0085 \mathrm{H}, \quad \psi_{f}=0.175 \mathrm{~Wb}$, $J=0.0008 \mathrm{~kg} \mathrm{~m}^{2}, P=4$. Outer loop speed loop sampling time is 10us, the inner current loop sampling time $10 \mathrm{u} \mathrm{s}$, the carrier frequency of PWM inverter is $500 \mathrm{kHz}$.

The SMO part of sensorless control system simulation model based on the conventional sliding mode observer as shown in figure 4 . and the sensorless control system simulation model based on sliding mode observer with phase-locked loop as shown in figure 5, The simulation model includes CLARK conversion module, PARK transform and inverse transformation module, SVPWM module, PMSM module, SMO (sliding mode observer) module and PLL (phase-locked loop). The establishment of SMO module is using the sliding mode observer model equation (4), (5), at the same time, in order to improve the simulation speed, a S function is written for the simulation, loaded a ready-written $M$ file called SMO directly in the Matlab/Simulink can finish operation function, the simulation model as shown in figure 6, PLL module as shown in figure 7 . During the process of simulation the perturbation factor and the inertia factor of system are ignored, meaning simulation system modeling was conducted under the condition of ideal. Due to motor model itself with position encoder, actual angle and rotational speed of the motor rotor can be obtained by the encoder signal.

In order to observe response ability of PMSM without position sensor system based on sliding mode observer for speed change and load torque change, using sliding mode observer with the switch gain was set to 200 . This article first makes the motor in the conventional sliding mode observer model and the motor in the sliding mode observer with a phase-locked loop model start up with no-load and sets the speed to $800 \mathrm{r} / \mathrm{min}$.In two models, the simulation waveforms of speed's real and the estimated values and the simulation waveforms of rotor's actual and the estimation position as shown below.

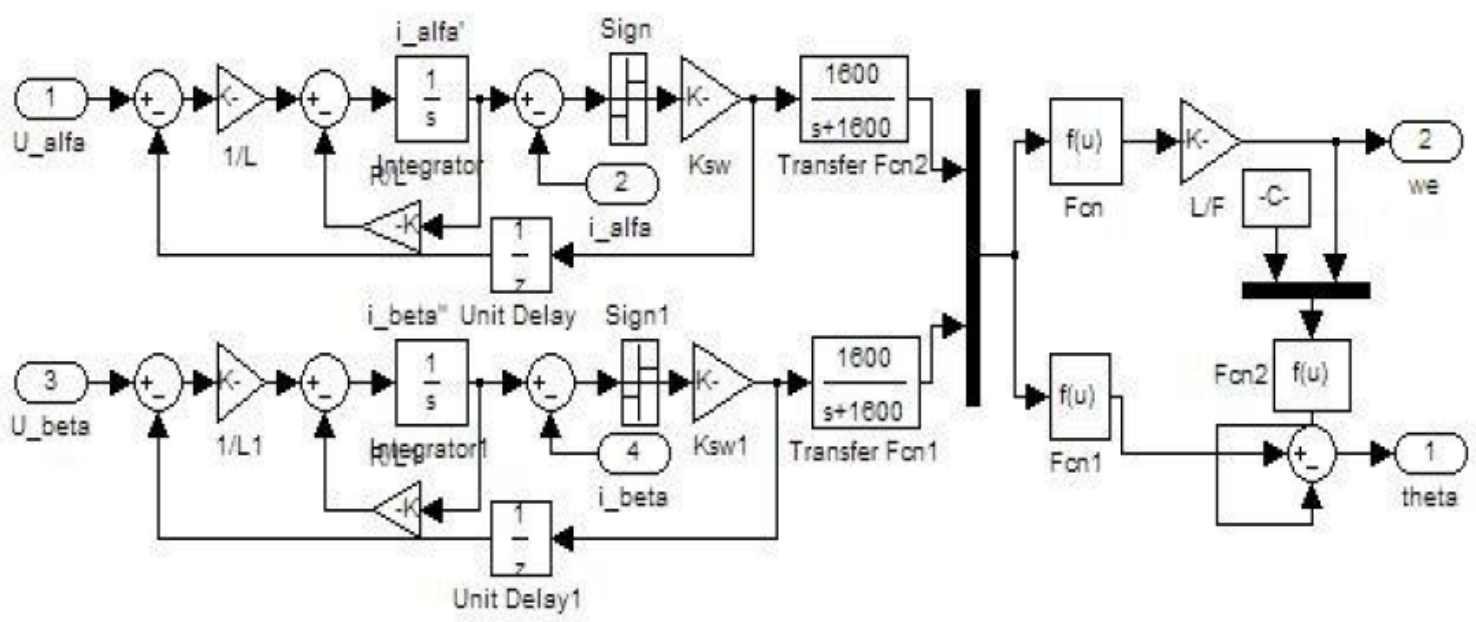

Fig.4. The sensorless control system SMO module based on sliding mode observer 


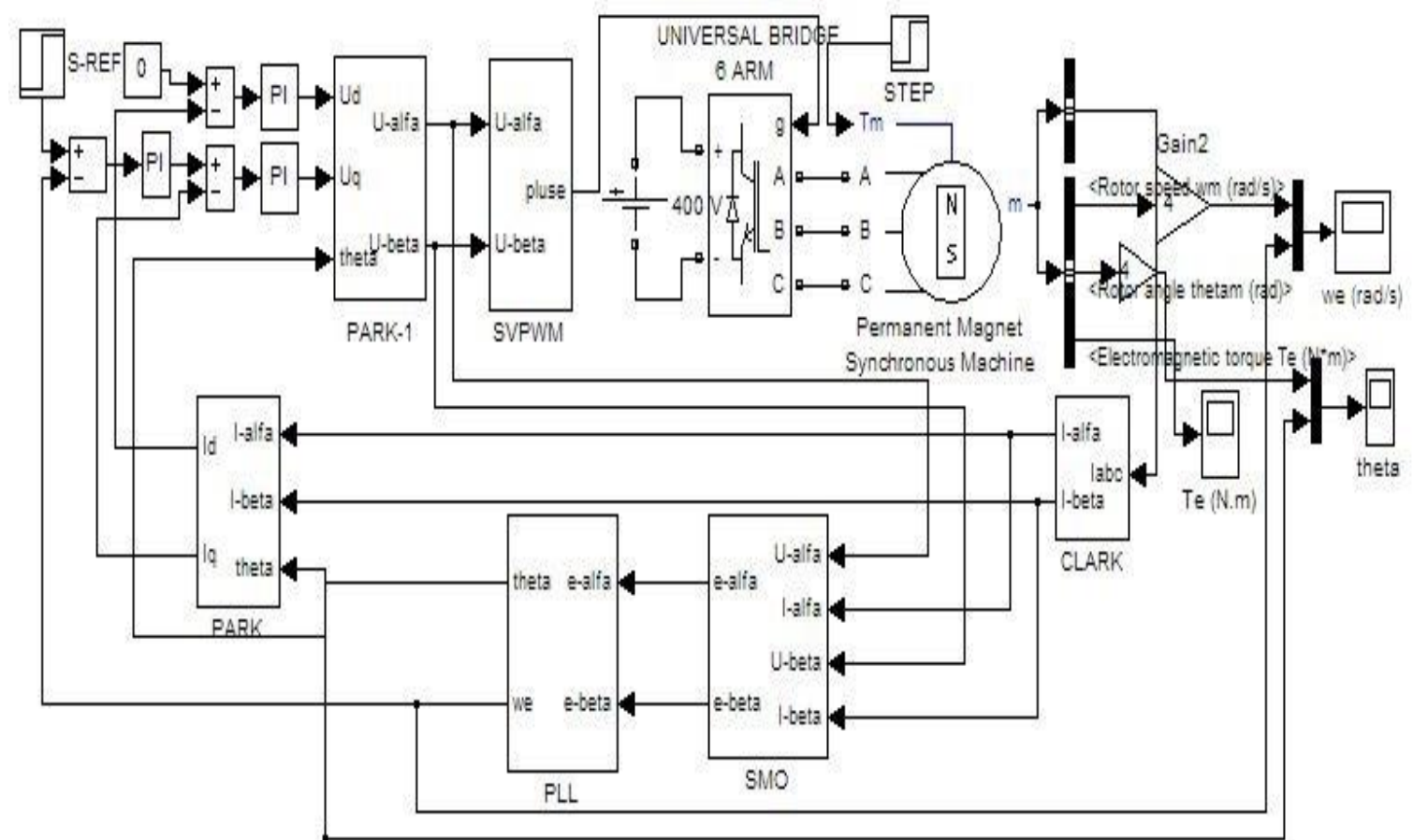

Fig.5. The sensorless control system simulation model based on the sliding mode observer with phase-locked loop

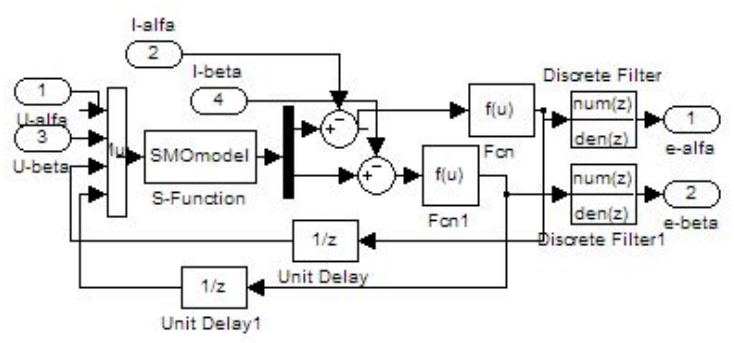

Fig.6. The SMO module

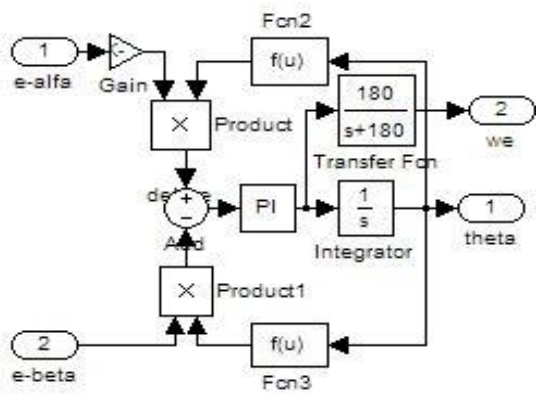

Fig.7. The PLL module

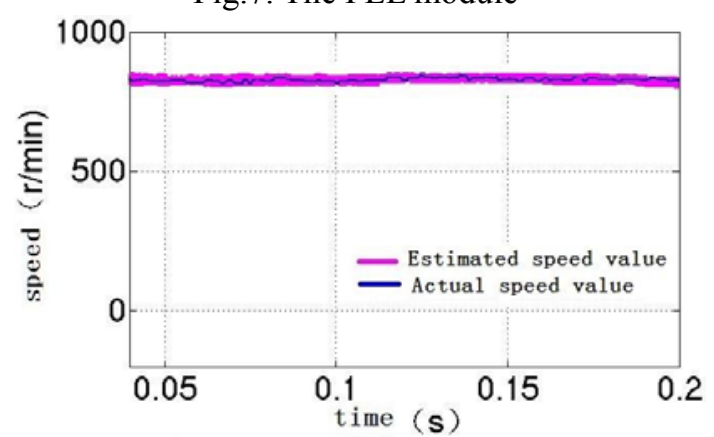

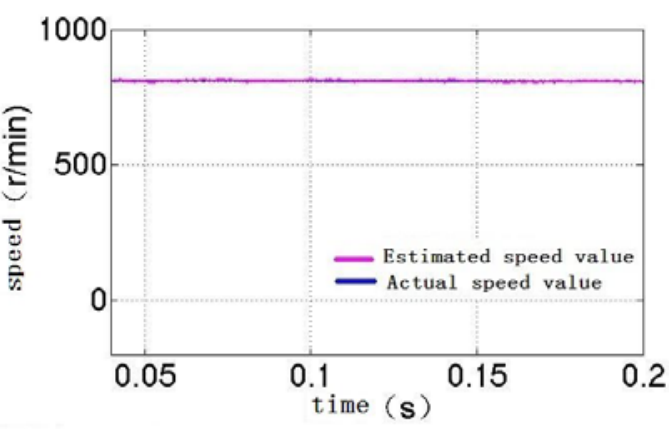

Fig.9. The speed based on the SMO and PLL control system

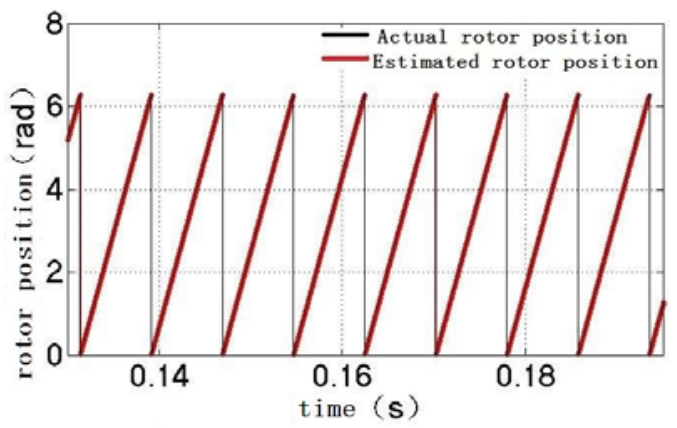

Fig.10. Rotor position based on SMO control system

Fig.8. The rotational speed based on SMO control system 


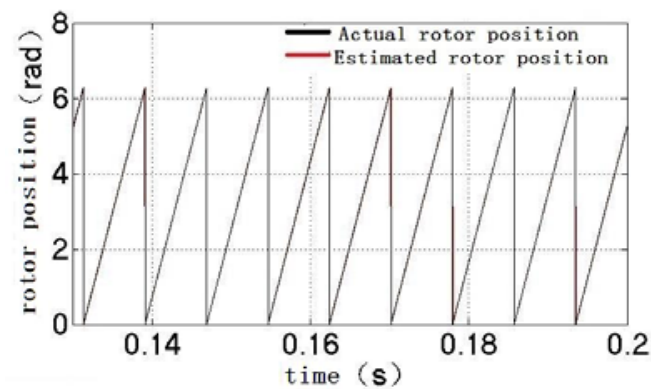

Fig.11. The rotor position based on the SMO and PLL control system

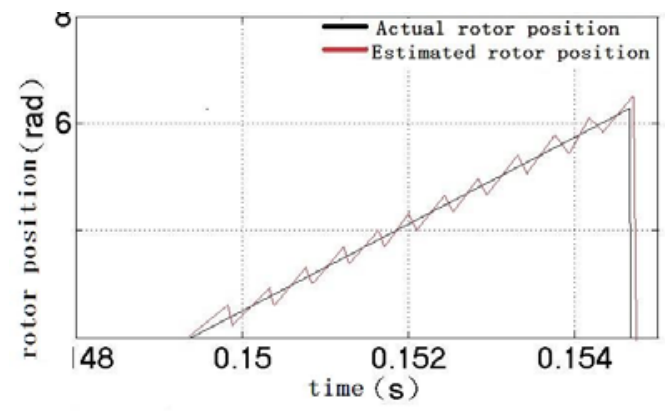

Fig.12. The rotor position partial enlargemen based SMO control system

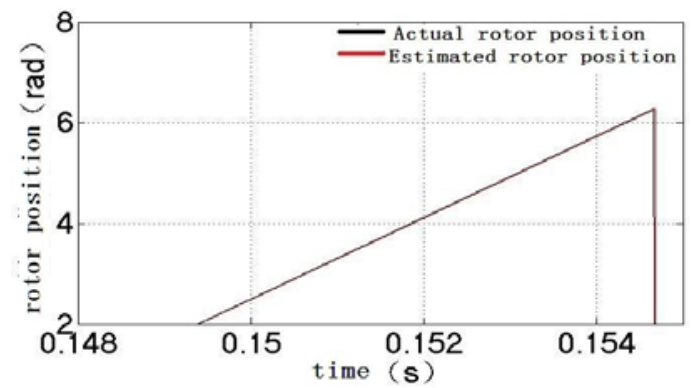

Fig.13. The rotor position partial enlarged based on SMO and PLL control system

From the comparison of above waveform, the rotational speed value can be estimated by using phase-locked loop, estimated speed waveform is more smooth, estimate speed value fluctuates up and down along the actual speed value, can fast track speed's changes, and the error between rotor estimation speed value and the actual value is less, and system run more stable.

Then makes the motor in the sliding mode observer model with a phase-locked loop start up with no-load at speed of $400 \mathrm{r} / \mathrm{min}$, and set the given speed is from $400 \mathrm{r} / \mathrm{min}$ up to $800 \mathrm{r} / \mathrm{min}$ at $0.1 \mathrm{~s}$. The simulation waveforms of speed's real and estimated values and the simulation waveforms of counter electromotive force estimates values under static coordinates as shown in the figure below.

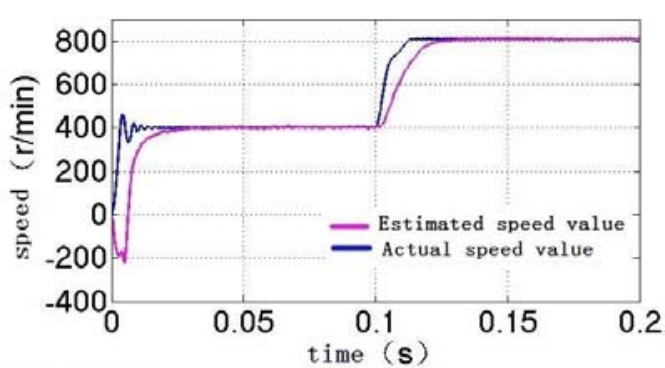

Fig.14. Speed change curve over time

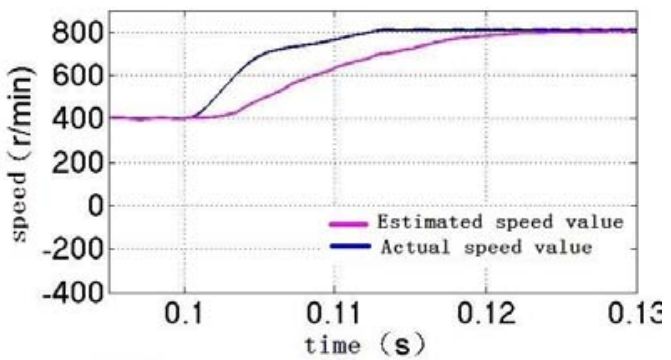

Fig.15. The partial enlargement of speed changing with time curve

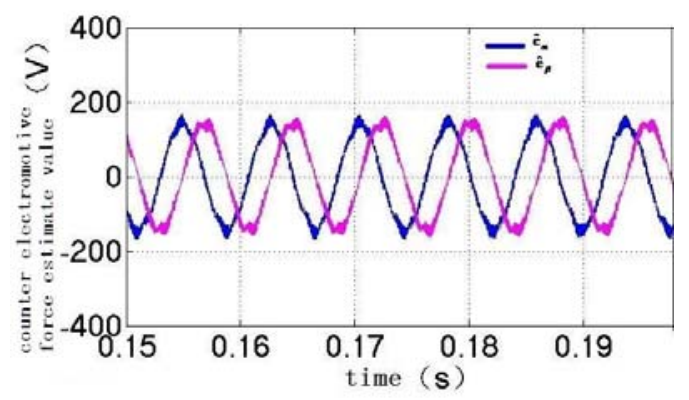

Fig.16. Counter electromotive force estimate values under static coordinates

From the above waveforms, in Fig14 and Fig15 the rotor speed from 0 up to $400 \mathrm{r} / \mathrm{min}$ in $5 \mathrm{~ms}$, the given speed from $400 \mathrm{r} / \mathrm{min}$ up to $800 \mathrm{r} / \mathrm{min}$ at $0.1 \mathrm{~s}$. Motor speed following the given value better, Speed rise time is $15 \mathrm{~ms}$. it show that when the motor start and speed change, control system for low jitter, smooth response, By comparison from waveforms can find the estimation error of just started is big, In the process of running can more accurately track the actual angle. Fig16 shows that the counter electromotive force estimate values under static coordinates.

Finally makes the motor in the sliding mode observer with a phase-locked loop model start up with no-load at speed of $400 \mathrm{r} / \mathrm{min}$, the given speed is from $400 \mathrm{r} / \mathrm{min}$ up to $800 \mathrm{r} / \mathrm{min}$ at $0.1 \mathrm{~s}$. The simulation waveforms of speed's real and estimated values and the simulation waveforms of torque and the simulation waveforms of the air-gap magnetic field track as shown below. 


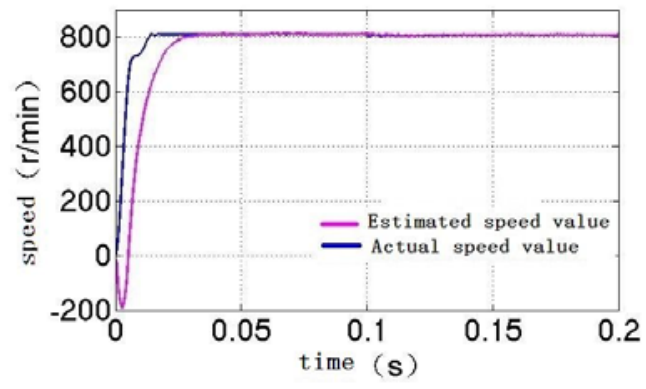

Fig.17. Speed change curve over time

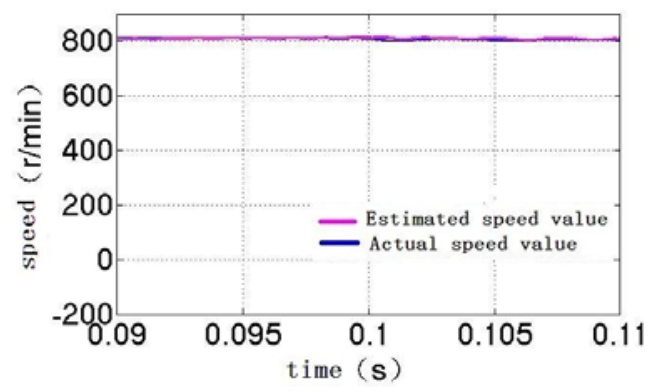

Fig.18. The partial enlargement of speed changing with time curve

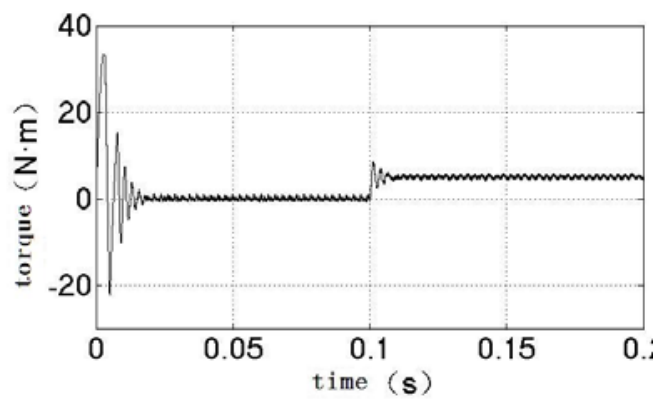

Fig.19. Torque curve changes over time

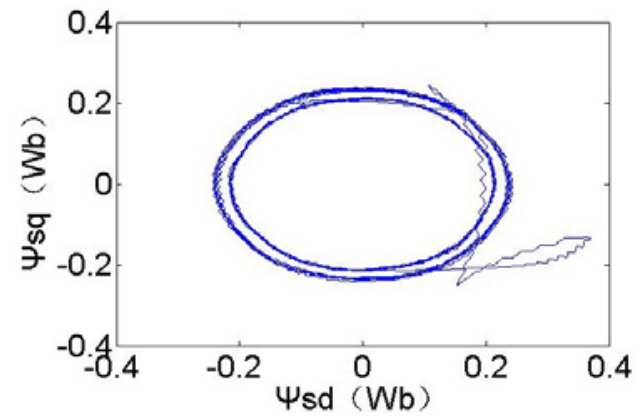

Fig.20. Air-gap magnetic field change track

From the above waveform, torque waveform is br oadly stable in Fig 19, when the load torque change fr om 0 to $5 \mathrm{~N} . \mathrm{m}$, the output torque of motor instant great ens and quickly achieve balance, this process costs 6 ms. Fig17 and Fig18 shows the change of the torque $h$ as no affect at the basic speed. Fig20 shows that contr ol system can form the air-gap magnetic field with hig her accuracy.

\section{Conclusions}

In this paper, a sliding mode observer-based position sensorless control scheme has been presented for PMSM drives. The stability of the proposed sliding mode observer has been proved by a Lyapunov stability analysis.

The proposed system comprises a sliding mode observer and a field-oriented PI current controller for the speed control loop. The SMO is used to estimate the rotor position and speed of the PMSM due to its strong robustness. Simulation results indicate the feasibility and effectiveness of the proposed control system.

\section{References}

(1) V.D. Colli and F. Marignetti, "A system-on-chip sensorless control for a permanent magnet synchronous motor," IEEE Trans. Ind. Electron., vol. 57, no. 11 , pp. 3822-3829, Nov. 2010.

(2) S. B. Lee and S. Nandi, "A new strategy for condition monitoring of adjustable speed induction machine drive systems," IEEE Trans. Power Electron., vol. 26, no. 2, pp. 389-398, Feb. 2011.

(3) S. J. Underwood and I. Husain, "On-line parameter estimation and adaptive control of permanent magnet synchronous machines," IEEE Trans. Ind. Electron., vol. 57, no. 7, pp. 2435-2443, Jul. 2010

(4) L. Idkhajine and A Maalouf, "Fully FPGA-Based Sensorless Control for Synchronous AC Drive Using an Extended Kalman Filter; IEEE Trans. Ind. Electron., vol. 59, pp. 3908-3918, Oct. 2012.

(5) Antti Piippo and Jorma Luomi, "Analysis of an Adaptive Observer for Sensorless Control of Interior Permanent Magnet Synchronous Motors," IEEE Transactions On Industrial Electronics. vol. 55, no. 2, pp. 570-576, February 2008.

(6) Holtz.J. "Sensorless control of induction machines - with or without signal injection?" IEEE Trans Ind. Electron, vol.53 no.1,pp:7-30, Dec. 2005

(7) Gilbert Foo, and M. F. Rahman, "Sensorless Sliding-Mode MTPA Control of an IPM Synchronous Motor Drive Using a Sliding-Mode Observer and HF Signal Injection ," IEEE Transactions On Industrial Electronics. vol. 57, no. 4, pp. 1270-1278, April 2010.

(8) K. Hongryel and L. Jangmyung, "A High-Speed Sliding Mode Observer for the Sensorless Speed Control of a PMSM," IEEE Transactions on Industrial Electronics, vol. 58, pp. 4069-4077, 2011 